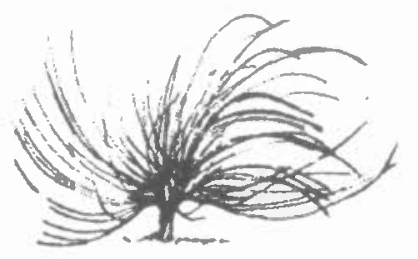

\title{
La escucha: el valor de la palabra
} hablada $^{1}$

\author{
Álvaro B. Márquez-Fernández ${ }^{2}$ \\ Universidad de Zulia, Venezuela \\ Venezuela \\ amarquezfernandez@gmail.com
}

\begin{abstract}
Resumen
La palabra recorre, a través del lenguaje, infinitos discursos comunicativos. La palabra nunca es única, absoluta o abstracta, aunque, a veces, en su silencio parezca ausente. Ella siempre es un surco que nos abre a la vida del sentido. Toda palabra es, entonces, apertura y acción expresiva, comunicativa. Esa es su forma de hablar, porque se convierte en escritura y verbo dialogante (de cualquier signo o icono, por simple que sea su grafia o forma),
\end{abstract}

Recibido: 08 de setiembre, 2010 - Aprobado: 29 de junio, 2011

1 Ponencia en el Seminario Internacional II sobre la Enseñanza de la Filosofia y IV sobre Filosofia para Niños y Niñas. 26 y 27 de Junio, 2008, CELARG, Caracas.

2 Profesor Emeritus de la Universidad del Zulia. Magister en Filosofia (LUZ). DEA y Doctor en Filosofia (Universidad de Paris I, Panteón-Sorbona, Francia). Responsable de los proyectos de investigación: "Interculturalidad y razón epistémica en América Latina" (CESALUS), "Red internacional de Investigación y Documentación sobre América Latina y el Caribe" (CONDES-LUZ); "El diálogo filosófico en la filosofia para Niños y Niñas de M. Lipman (Centro de FpN, UNICA). Director de la revista Utopía y Praxis Latinoamericana (CESA-LUZ), Coordinador de la Maestria en Pensamiento Latinoamericano (UNICA). PPI. Nivel IV (FONACIT). Autor de varios libros y numerosos artículos relacionados con Ética, Filosofia política Latinoamericana, Estética, Epistemología y Filosofia para Niños y Niñas. Pertenece al Comité de Árbitros y al Consejo Editorial de varias revistas nacionales e internacionales. También es miembro activo de varias redes de investigación sobre Pensamiento Político Latinoamericano. 
para dar a luz ese cuerpo visual y auditivo con el que se descubre frente a si y a los otros que son sus receptores, sus audio-escuchas, video-escuchas, radio-escuchas, tele-escuchas...fono-escuchas. Es en el escuchar la(s) palabra(s) de unos y otros, donde el ser de la realidad se hace posible para todos. Aprender a escuchar es aprender a vivir de y con la(s) palabra(s), que son las que nos hablan con todas las razones de los sentidos.

Palabras claves: Palabra(s), escucha(r), dialogante(s), razón(ar).

\begin{abstract}
The word wanders through infinite language communicative discourses. The word is ncver unique, absolute, or abstract, even when its silence seems absent. It is always a source that brings meaning to life. Any word means openness and expressive action. It is its way of talking because it becomes writing and a dialoguing verb (any sign, icon, graph, or shape) in order to create that visual and audible body that becomes meaningful to itself and to other receptors -its audio-listeners, video-listeners, radio-listeners, TV-listeners...phono-listeners.- It is in this process of listening to a word or words where the reality of being becomes real. Learning how to listen is learning how to live from and with the word or words which are the ones that talk with all the reason senses.
\end{abstract}

Keywords: Word, listening, dialoguing, reason, reasoning.

Para Diego Pineda: Revelación de las palabras, Exclamación de la voz... 
$\mathrm{O}$

\section{Palabra, hablar y voz}

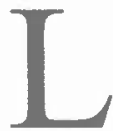

a vida no es solamente una conciencia y un pensamiento. Es también una forma material y corporal, es la voz de la conciencia y las palabras del pensamiento. Varios son los sentidos de nuestros cuerpos que utilizamos para percibir la realidad que nos transforma y que a la vez re-transformamos. El mundo que nos rodea responde y es estímulo a nuestros sentidos del gusto, tacto, olfato, mirada y oídos. La relación de nuestros sentidos con la experiencia humana de la vida es necesariamente existencial y sensible. ${ }^{3}$ Pero, también, consciente. Por lo que nuestra percepción de la realidad es una experiencia producida por nuestra conciencia a través de los sentidos; además, es una experiencia que incide sobre nuestro pensamiento reflexivo; y, finalmente, una experiencia subjetiva que resulta de nuestros actos intencionales con la finalidad de dotar de significación comunicativa a las prácticas lingüísticas. ${ }^{4}$

Nos creamos un mundo de interacciones donde el sentido de nuestras prácticas sensibles y cognoscibles son, en efecto, sistemas de relaciones semióticas que nos permiten comprender en su pragmática la realidad como un conjunto complejo de sistemas de interpretación lingüística, que se reorganizan a través de diversos códigos que pueden responder a los múltiples sentidos de nuestra materialidad corporal y nuestra abstracción racional.

Por una parte, nos situamos en el mundo de las sensaciones por medio del lenguaje del cuerpo, ${ }^{5}$ aún reprimido por las normas sociales que impiden la libre manifestación de sus signos. Hemos perdido nuestra capacidad corpórea para expresarnos. Necesitamos recuperar los sentidos de nuestros cuerpos para ampliar los accesos de la interpretación sensorial. Por la otra, es un requerimiento desarrollar esa particular y personal conciencia que es la conciencia de los sentidos de nuestra habla, que se practica con el discurso de las palabras. Aprendemos a componer, estructurar con las palabras lo que pensamos y sentimos. Es ese orden de la gramática del sentido y el símbolo, con el que nos reencontramos en el mundo para gustar(nos), mirar(nos), oler(nos), tocar(nos), y, en especial, escuchar(nos). El cuerpo de la palabra y las

Ortiz-Osés A. (2000). La razón afectiva. Ed. San Esteban, Salamanca.

Nicol, E (1989). La primera filosofía de la praxis. FCE, México.

Merleau-Ponty, M (1972). Phénoménologie de la perception. Gallimard, Paris, Francia. 
palabras del cuerpo, sería la afectiva correlación entre estos dos mundos de las percepciones y sensaciones, y el del sentido y el de la existencia. ${ }^{6}$

Es imperativo descubrir el contenido expresivo de nuestros cuerpos y el de las palabras, y sobre todo el de esa conciencia intencional que subyace en cada uno de éstos: el de la conciencia objetiva que surca por las orillas y contornos de una geografía corporal que nos imprime sus formas físicas; el de la conciencia subjetiva que surca por la imaginación de unos y otros para construir y reconstruir los conceptos y las metáforas de la realidad.

Es necesario aprender a descubrir y educar los sentidos para que las relaciones entre cuerpo y palabra sean lo más originarias en su expresión y expuestas en su libertad. Esta tarea de aprendizaje es y debe responder a todo un proyecto filosófico de vida. Es decir, a un modo de ser que reconozca en el cuerpo y la palabra una experiencia de pensamiento sensible y racional.

Para el caso que nos ocupa y deseamos reflexionar, consideramos que no es posible el diálogo y un proceso de resignificación en cada una de las palabras del diálogo, si no disponemos de condiciones para la escucha. ${ }^{7}$ Un ámbito de la vida de los sentidos físicos del cuerpo, como lo es el oído que requiere una gimnasia permanente para afinar el oído como instrumento musical. Nos interesa disponer de los sentidos físicos del cuerpo con un nivel de destreza y dominio, que podamos valernos de ellos para sentir la manifestación natural y cultural del mundo. Estamos dentro del paisaje de la naturaleza dotados de capacidades mucho más complejas que cualquier otro ser vivo. Sin ser águilas o halcones, podemos "mirar" el mundo que deseamos contemplar e interpretar con igual o mayor velocidad, entre el vuelo de las aves de pluma y nuestros vuelos con alas tecnológicas. Para ser buenos escuchas, debemos valernos de un uso físico de nuestros aparatos auditivos para escuchar todo lo más posible qué es lo que es sonoro en el mundo. ${ }^{8}$ Para ser buenos escuchas entre quienes hablan y se hablan, debemos ser buenos receptores cognitivos del lenguaje y sus palabras. La presunción de todo uso

6 Márquez-Femández, A (2008): “La libertad sensible: más allá de la represión racional del cuerpo". Educação e linguagem. Título do Dossiê: Corpona Educação: culturas e prácticas educativas.m Ano: 11, n, 17. Jan-Jun. São Bernardo do Campo, SP: Metodista, Brasil. Nancy, J-L (2002). À l'écoute. Galilée, Paris.

Nicol, E (1989). Op. cit., p. 45 
de la palabra es el uso de un lenguaje, la presunción del uso del lenguaje es la comunicación con unos y otros. ${ }^{9}$

De los diversos procesos que pueden formar parte de una definición o características del lenguaje, está sin mayor discusión la del diálogo. La necesidad que tienen los interlocutores de hablarse está impregnada y atravesada por la presencia de todos los sentidos. Nuestra comprensión de las palabras es múltiple y diferenciada según el uso y las relaciones que podamos conectar con cada uno de los sentidos. Pero el sentido que está en mayor correspondencia con la palabra es el oído que nos permite aprender a usarlo como un receptor de la escucha del otro. ${ }^{10}$ La mirada pudiera darnos otra "escucha" de la palabra en un sentido más amplio, pero acá se trata de la palabra hablada en sus unidades físicas de voz y de sentido fonológico y semiótico. Nos referimos a la naturaleza primaria de la palabra con su eco que sería la escucha de uno mismo y otro u otros. Así que la palabra se hace voz y es de otra manera muy diferente a la palabra que se hace escritura y se lee con la mirada, aunque se puede interesar en indagar imaginariamente el mundo de la escucha...

En su presencia sonora, la palabra es voz y convoca al otro a un compartir y sentir lo que la palabra transmite en su habla. Es ese encuentro el que hace posible la alteridad de la palabra con el otro que la escucha. "Ése que la reconoce en sus códigos y quien en el acto particular de cada palabra escuchada, se puede recrear el sentido de la palabra y sus significaciones... Pero el sentido de las palabras es crear, por medio de su escucha, otras palabras con las que los otros nos hablan desde sus universos respectivos. El significado de las palabras para quien las escucha siempre está abierto a la deliberación de lo que con ellas se expresa y comunica.

Toda palabra gesta una reciprocidad que le sirve de autoreferencia y contexto significativo. Esto le permite al usuario de la palabra saber, entre otras cosas, lo que está pensando, y el deseo de compartir ese pensamiento con otros de forma recíproca. Lo que supone un esfuerzo reflexivo por aprender a escuchar lo que se habla con las palabras, y en este nivel hermenéutico la palabra se hace intuición para el diálogo:

9 Lafon, C (1993). La razón como lenguaje. Visor, España

10 Buber, M (1992). Yo y Tú. Caparrós Ed. $4^{2}$ ed. España.

1 Valera-Villegas, G (2002). Pedagogía de la alteridad. Una dialógica del encuentro con el otro. Facultad de Humanidades y Educación, Universidad Central de Venezuela, Caracas. 
i) por su sentido ya que necesitamos comprender lo que se dice con las palabras transformando la escucha en un acto de atención que nos permita reconocer el derecho a decir la palabra sin interponer ningún tipo de coacción y/o censura que impida la libertad de la palabra; ii) por su significado, ya que necesitamos interpretar lo que porta la palabra a través de un diálogo donde la palabra queda expuesta al otro en toda su opacidad e intencionalidad subjetiva. Es precisamente, este proceso el que nos induce o exhorta a deliberar el sentido con el que percibimos las palabras que escuchamos. El diálogo será la esfera de movilidad donde podemos indagar y explorar los sistemas de valores, representaciones, intereses, que portan las palabras a las que nos vamos acercando por su opacidad a relaciones siempre interactivas que estimulan nuestra capacidad analítica y crítica. La palabra y su escucha es la principal manifestación de la conciencia racional y sensible.

\section{La audición y la audiencia de las palabras. No más "diálogos de sordos"...}

Es imposible escuchar sin hablar, o sea, sin decir palabra. No se puede escuchar con la mirada. La palabra entonces es, en su génesis, verbal. La palabra no verbal, la palabra sin voz, es una meta-palabra encarnada en los signos de los gestos corporales o por los artificios de la escritura. Sin embargo, la palabra del diálogo es la palabra de la escucha, no la de la imagen, aunque nos la podamos imaginar o representar. No validamos la afirmación de que "una imagen vale más que mil palabras". La imagen de las palabras, el orden visual que la constituye más allá de la presencia de su voz, es un meta-sentido que portan las palabras.

Se pudiera afirmar lo que expresamos, por ejemplo, de la caligrafia, como una instancia de la forma o imagen que logran las palabras a través de la escritura. Pero las palabras escritas no se escuchan, para que éstas hablen necesitan de la voz. Una, es la palabra-imagen, que "dice de ella misma"; la otra, es la palabra-voz, que habla desde el otro. Dos planos ontológicos, donde una pudiera ser considerada más próxima de los objetos de la realidad, mientras que la otra está más en curso de las subjetividades de la realidad.

Acá sólo nos referimos a la denotación de las palabras en sus usos. Sin embargo, la carga significante y simbólica de ambos planos 
ontológicos de la palabra, nos abre plenamente a una hermenéutica que nos da la posibilidad de dialogar con las imágenes. Precisamente, eso significa introducir en las voces del diálogo otra dimensión de la escucha que nos haría posible ser receptores y receptivos del lenguaje de las palabras que connotan las imágenes.

Las palabras requieren de un auditorio, de una audiencia. Es decir, de los que son oyentes, de quienes deben y necesitan escuchar lo que se habla.

Se trata de aprender a descubrir ese campo de frecuencia enunciativa y sonora del espacio de las palabras, para convertirlas en el discurso de quien las pronuncia y en el tránsito dialógico con el que se recuperan las palabras a través de los otros, considerados como sus receptores emisores. Pero ahora, la recepción de éstas se logra en otra escena del discurso hablado, un escenario donde la palabra adquiere su significación gracias a la escucha que nos solicita. ${ }^{12}$

A ese dominio o campo de la escucha donde nos sitúan las palabras habladas, es al que le debemos otorgar mayor cuidado para enriquecernos con sus polifonías. Debemos aprovechar la experiencia del habla para matizar los sentidos de cada palabra, a través de sus sonoridades. En ese juego de sonidos y de matices donde las palabras se nos abren a cada uso del lenguaje, y se recrean en el pentagrama de sus tonalidades. Es cierto, por un lado, la palabra se convierte en un acto de la voz; pero, por el otro, en una acción comunicativa para la escucha. Lo que transcurre entre el acto y la acción, es la polivalencia de la palabra al convertirse en un signo: esa recreación permanente por el sentido subjetivo de la significación. La palabra es una y otra en un devenir incesante.

En su condición material la palabra es un acto fónico y/o gráfico; en su acción, la palabra es el código tonal que resulta de la conciencia que precipita en su fuerza auditiva y se recupera en la escucha del otro. Se podría considerar que la palabra como revelación sensible del sujeto, es un pensar que se manifiesta en el mundo por medio de una voz que se declara siempre expectante; simultáneamente, en su concreción pragmática, ella es la mediación para el discurso del habla. ${ }^{13}$ Es decir, los ritmos vocales de las diferentes voces transforman, en un sonoro

12 Foucault, M (1996). La hermenéutica del sujeto. FCE, México.

13 Nicol, E (1989). Metafisica de la expresión. FCE, México. 
lenguaje a las palabras; pero también, las diversas decodificaciones que éstas reciben a través de la escucha.

Se trata, precisamente, de comprender esa fenomenología de las voces para pronunciar las palabras que serán objeto del discurso y serán prácticas dialógicas. La pregunta por el sentido de la palabra, nos incita a descubrir sensiblemente el cosmos de la voz, ese universo de sonidos decibles e indecibles que portan las palabras y que requiere de una especial semiótica para saber situarnos en los contextos de los actos conscientes e inconscientes, donde las palabras nos transportan y forman parte de la experiencia de pensamiento de la vida del hablante. ${ }^{14}$

A esa interioridad subjetiva del signo-significado de las palabras del sujeto es que se abren y buscan los accesos, el discurso del interlocutor que escucha. Pueden ser numerosas las razones o condiciones para una falta o ausencia del oyente. En cualquier caso las debilidades o déficit del escuchar, lesiona fuertemente la existencia y presencia de la palabra. La asociación entre palabra, voz y escucha es recurrente. No se puede prescindir de ninguno de los elementos de esta correlación. Lo que nos hace suponer que del mismo modo en que aprendemos a hablar, a escribir o leer, deberíamos aprender a escuchar. Y seguidamente: así como el aprendizaje del habla nos debería convertir en competentes dialogantes, el aprendizaje del escuchar, nos debería convertir en competentes oyentes. ${ }^{15}$

Es muy probable que a falta de este aprendizaje sobre lo que es el derecho a la escucha de quien habla, y las competencias que debe portar un buen oyente, es que el diálogo se ve imposibilitado y pierde su potencialidad dialógica, porque la palabra sin voz es un sin sentido, y la voz sin oyentes es un contrasentido. ${ }^{16}$ La posibilidad de un "diálogo de sordos", es una imposibilidad por el absurdo que implica. Es imprescindible para dialogar, aprender a pensar con la palabra. No es posible ninguna resistencia que anule, extinga, neutralice o niegue la palabra. Esta es la dación del ser pensante. El destino de toda palabra es la libertad para hacer la práctica, es decir para hablarla de cara a los otros. Es un poder que declara la palabra públicamente.

14 Kohan, WO (2004). Infancia, entre educación y filosofia. Alertes, Argentina.

is García Morrión, F (2006). Pregunto, dialogo, aprendo. Ed. de la Torre, Madrid, España.

16 Pérez-Estévez, A (2008). Hermenéutica dialógica. Ediciones de la Universidad Católica Cecilio Acosta, Maracaibo, (e.p).Pérez-Estévez, A (2008). Hermenéutica dialógica. Ediciones de la Universidad Católica Cecilio Acosta, Maracaibo, (e.p).Pérez-Estévez, A (2008). Hermenéutica dialógica. Ediciones de la Universidad Católica Cecilio Acosta, Maracaibo, (e.p). 
De igual modo, aprender a pensar por la escucha es complemento, no suplemento o accidente, de la realidad presencial de la palabra ante los otros. La escucha presupone la palabra que dota al oyente de capacidad dialógica. Sin la escucha del oyente, la palabra es inexistente. La palabra es por la alteridad de la que recibe y manifiesta su ser sentido, pensado, comunicado, significado. El diálogo que se suscita entre la palabra y el oyente que la asume, reproduce y la transmite, en un recurso sin determinaciones o límites, es lo que le permite a la palabra su trascendencia. Es decir, hacerse de una resignificación permanente por una constante recreación que proviene del oyente quien también es su usuario. El oyente que escucha la palabra la reconstruye en todas sus tramas significantes... Esto nos permite considerar que el diálogo, ése que presume de mayor autenticidad, autonomía y libertad, deberá ser aquel que se genera entre hablantes -que por derechos comunicativos son escuchados- y entre oyentes que se transforman en hablantes porque se les reconocen estos derechos compartidos. Es una especie de unidad dentro de la diversidad.

El telos de la palabra es su diá-logos. Pero también posee una audición comunicativa que despierta nuestra imaginación para pensar con esa voz pasiva o activa, mientras escuchamos o se nos escucha. El aprendizaje de un oyente, es decir, el que piensa escuchando, el que habla para pensar en lo que ha escuchado y para repensar en lo que le han enseñado a escuchar, es el sujeto de una práctica comunicativa donde la palabra es empática: lo que ella significa transmite una experiencia de valor en común para todos los interesados en el habla. ${ }^{17}$

Es el modo de asociación comunicativa y discursiva de la palabra en el intercambio de los discursos. La proyección de la palabra en sus diversas esferas del lenguaje, nos permite conocer el mayor número posible de universos de representación y simbolización de la palabra, ya que dispone de una porosidad textual que le permite infiltrar por completo el mundo de la realidad. La palabra es ontocreadora, ${ }^{18}$ a través de ella el ser que somos y la existencia que es, adquiere las dimensiones del tiempo y los espacios donde nos realizamos. El presente que es pasado, el futuro que se espera desde el presente, los cambios de lugares entre el ayer y el hoy o el mañana, nos lo dicen el lenguaje de las palabras. $Y$

\footnotetext{
Nicol, E (1982). Crítica de la razón simbólica. FCE, México.

18 Ibidem.
} 
hablamos conjugando en tiempos y espacios las palabras... El ser que somos, fuimos y posiblemente seremos...

El diálogo desde la palabra que se escucha, recrea el diálogo por mediación de la palabra del otro, pues se habla de lo hablado desde diferentes horizontes que tienden a ser incluyentes. ${ }^{19}$ Son dos hablantes que entran en una relación dialógica que necesariamente resulta de la alteridad de la palabra y sus contextos. La interpretación de la palabra surge de un proceso abierto del sujeto interprete que acepta la interpelación o desafio de la palabra del otro, que sugiere una o más significaciones.

El diálogo es la exploración de la opacidad e incertidumbre que destila en toda palabra, lenguaje y discurso en su incesante inmanencia semiótica. El intento de pensar desde el habla que se escucha por la presencia del otro, es un intento de comunicación que requiere hablar desde una alteridad originaria que culturalmente se debe historizar. Es decir, abrir el sistema de significación a la compleja red de sentidos que lo tejen. Sin escuchar al otro, sin concederle el derecho a su palabra, sin ejercer intento alguno por negarle el habla; no es posible reconocerlo como un interlocutor. La otra palabra que se exterioriza profiere a través de la voz muchas realidades que desean manifestarse. Es importante que la situación de tiempo y espacio del oyente, le permita pensar, sentir y hablar desde una diferencia - pues nunca se está con el otro en una perfecta armonía o analogía- donde el otro se presenta múltiple e inagotable. La escucha del otro que habla en el diálogo, convierte al oyente en un escuchar que privilegia la audiencia: es decir, el uso de las significaciones que recorren el discurso entre uno y otro para producir la hermenéutica del sentido.

Esa convivencia con las prácticas discursivas en las que el habla encuentra y alcanza su reconocimiento semio-pragmático, nos permite una comunicación desde la alteridad que sugiere otras formas de codificación y reinterpretación que disminuyen proporcionalmente la opacidad o ambigüedad de las palabras. Ese ejercicio de dilucidación reflexiva y crítica de los sentidos de la palabra, genera una praxis de la escucha que permite interpretar las palabras por su sonoridad, su audición, las escalas de la voz, y poder hilar y tejer en torno al uso de las palabras sus significaciones y sentidos. Lo que la voz le porta a la palabra ésta

Barrena, S (2007). La razón creativa. Crecimiento y filosofia del ser humano según C. S. Peirce. Rialp, Madrid. 
lo transporta a la comunicación. Es indiscutible el secuestro del que ha sido objeto la palabra por el dominio de un habla social que restringe o minimiza la riqueza vocal o auditiva de la palabra, desacreditando gran parte de su valor comunicativo.

Es tanto así, que no siempre por el acto de hablar esto supone la certeza de saber qué es lo que se escucha. Para hacer del habla un acto de competencias auditivas -además de las lingüísticas- se requiere que el habla reporte en su sonoridad los sentidos que transmite la voz, sin la que no es posible disponer de un discurso para el oyente que escucha. Esta dimensión del discurso fónico que contiene un amplísimo margen de ambigüedad y opacidad, es el que debe someterse al razonamiento de las audiencias respectivas, para conocer quiénes son los otros por medio de sus palabras. Para enseñar a pensar es preciso, sobre todo, aprender a escuchar: es la inevitable consecuencia humana -racional y sensible- para la creación del diálogo con el otro.

\section{REFERENCIAS}

Barrena, S (2007). La razón creativa. Crecimiento y filosofia del ser humano según C. $S$. Pierce. Rialp, Madrid.

Buber, M (1992). Yo y tú. Caparrós Ed. 4" ed. España.

Foucault, M (1996). La hermenéutica del sujeto. FCE, México.

Garcia Morrión, F (2006). Pregunto, dialogo, aprendo. Ed. de La Torre, Madrid, España.

Kohan, WO (2004). Infancia, entre educación y filosofia. Alertes, Argentina.

Lafon, C (1993). La razón como lenguaje. Visor, España.

Márquez-Fernández, A (2008). "La libertad sensible: más allá de la represión racional del cuerpo". Educação e linguagem. Título do Dossiê: Corpo na educação. culturas e prácticas educativas. Brasil.

Merleau-Ponty, M (1972). Phénoménologie de la perception. Gallimard, Paris, Francia. Nancy, J-L (2002). À l'écoute. Galilée, París.

Nicol, E (1989). Metafisica de la expression. FCE, México.

Nicol, E (1982). Crítica de la razón simbólica. FCE, México.

Nicol, E (1989). La primera fllosofia de la praxis. FCE, México.

Ortiz-Osés A (2000). La razón afectiva. Ed. San Esteban, Salamanca.

Valera-Villegas, G (2002). Pedagogía de la alteridad. Una dialógica del encuentro con el otro. Facultad de Humanidades y Educación, Universidad Central de Venezuela, Caracas. 